\title{
Identifying suitable reference genes for gene expression analysis in developing skeletal muscle in pigs
}

\author{
Guanglin Niu ${ }^{1,2}$, Yalan Yang ${ }^{1,2}$, YuanYuan Zhang ${ }^{1}$, Chaoju Hua ${ }^{1}$, Zishuai Wang ${ }^{1}$, Zhonglin Tang ${ }^{\text {Corresp., }}{ }^{1,2}$, \\ Kui Li ${ }^{1,2}$ \\ ${ }^{1}$ The Key Laboratory for Domestic Animal Genetic Resources and Breeding of Ministry of Agriculture of China, Institute of Animal Science, Chinese \\ Academy of Agricultural Sciences, Beijing, China \\ ${ }^{2}$ Agricultural Genome Institute at Shenzhen, Chinese Academy of Agricultural Sciences, Shenzhen, China \\ Corresponding Author: Zhonglin Tang \\ Email address: zhonglinqy_99@sina.com
}

The selection of suitable reference genes is crucial to accurately evaluate and normalize the relative expression level of target genes for gene function analysis. However, commonly used reference genes have variable expression levels in developing skeletal muscle. There are few reports that systematically evaluate the expression stability of reference genes across prenatal and postnatal developing skeletal muscle in mammals. Here, we used quantitative PCR to examine the expression levels of 15 candidate reference genes ( $A C T B, G A P D H, H P A R 1, R H O A, R P S 18, R P L 32$, PPIA, H3F3, API5, B2M, $A P 1 S 1, D R A P 1, T B P, W S B$, and $V A P B)$ in porcine skeletal muscle at 26 different developmental stages (15 prenatal and 11 postnatal periods). We evaluated gene expression stability using the computer algorithms geNorm, NormFinder, and BestKeeper . Our results indicated that GAPDH and ACTB had the greatest variability among the candidate genes across prenatal and postnatal stages of skeletal muscle development. RPS18, API5, and VAPB had stable expression levels in prenatal stages, whereas API5, RPS18, RPL32, and H3F3 had stable expression levels in postnatal stages. API5 and H3F3 expression levels had the greatest stability in all tested prenatal and postnatal stages, and were the most appropriate reference genes for gene expression normalization in developing skeletal muscle. Our data provide valuable information for gene expression analysis during different stages of skeletal muscle development in mammals. This information can provide a valuable guide for the analysis of human diseases. 
$1 \quad$ Identifying suitable reference genes for gene expression analysis in developing

2

3

4

6

$7{ }^{1}$ The Key Laboratory for Domestic Animal Genetic Resources and Breeding of Ministry of

8 Agriculture of China, Institute of Animal Science, Chinese Academy of Agricultural Sciences,

$9 \quad$ Beijing 100193, P. R. China

10

2 Agricultural Genome Institute at Shenzhen, Chinese Academy of Agricultural Sciences,

11

Shenzhen, 518124, P. R. China

12

* These authors contributed equally to this work.

13

\#Corresponding author:

Zhonglin

Tang,

Email:

tangzhonglin@caas.cn

or

zhonglinqy_99@sina.com 


\section{Abstract}

18 The selection of suitable reference genes is crucial to accurately evaluate and normalize the relative 19 expression level of target genes for gene function analysis. However, commonly used reference genes 20 have variable expression levels in developing skeletal muscle. There are few reports that systematically 21 evaluate the expression stability of reference genes across prenatal and postnatal developing skeletal 22 muscle in mammals. Here, we used quantitative PCR to examine the expression levels of 15 candidate reference genes (ACTB, GAPDH, HPAR1, RHOA, RPS18, RPL32, PPIA, H3F3, API5, B2M, AP1S1, $D R A P 1, T B P, W S B$, and $V A P B)$ in porcine skeletal muscle at 26 different developmental stages (15 prenatal and 11 postnatal periods). We evaluated gene expression stability using the computer algorithms geNorm, NormFinder, and BestKeeper. Our results indicated that GAPDH and $A C T B$ had the greatest variability among the candidate genes across prenatal and postnatal stages of skeletal muscle development. RPS18, API5, and $V A P B$ had stable expression levels in prenatal stages, whereas API5, RPS18, RPL32, and $H 3 F 3$ had stable expression levels in postnatal stages. API5 and $H 3 F 3$ expression levels had the greatest stability in all tested prenatal and postnatal stages, and were the most appropriate reference genes for gene expression normalization in developing skeletal muscle. Our data provide valuable information for gene expression analysis during different stages of skeletal muscle development in mammals. This information can provide a valuable guide for the analysis of human diseases. 


\section{Introduction}

Gene expression analysis provides important information for the study of gene function.

Reference genes are used to judge gene expression levels and changes in target gene expression. Quantitative PCR (qPCR) is an important method in evaluating gene expression, which was first invented by Applied Biosystems Corporation (USA) in 1996. This technology significantly advanced gene quantitative research, and provided high sensitivity, specificity, and accuracy (Mackay 2004; Valasek \& Repa 2005). Quantitative PCR analysis can be used to explore differences in gene expression at different developmental periods or under different conditions. The selection of appropriate reference genes for qPCR analysis can improve the accuracy and reproducibility of the study by normalizing the expression of target genes with respect to the expression of a selected standard gene (Huggett et al. 2005). However, the qPCR method can be affected by reaction parameters such as template quality, operating errors, and amplification efficiency (Bustin 2002; Gabert et al. 2003; Ginzinger 2002; Vandesompele et al. 2002; Wolffs et al. 2004; Yeung et al. 2004). Thus, qPCR data should be normalized with respect to one or more constitutively expressed reference or housekeeping genes, which corrects for experimental variability in some parameters.

Reference genes have to be validated and consistently expressed under various circumstances. Widely used reference genes for expression analyses include $G A P D H, A C T B$, and HPRT (Blaha et al. 2015; Boosani et al. 2015; Wang et al. 2016a; Zhang et al. 2016b; Zhao et al. 2015). These genes are reported to have consistent expression levels under various conditions such as different organs and different developmental stages (Tang et al. 2007). However, expression of these selected reference genes has not proven to be as stable as originally presumed, and their expression can be highly variable under different conditions (Jain et al. 2006; 
59

60

61

62

63

64

Wan et al. 2010; Wang et al. 2015). Therefore, qPCR has been used to identify appropriate reference genes in humans (Andersen et al. 2004; Warrington et al. 2000), animals (McCulloch et al. 2012, Martinez-Giner et al. 2013; Robledo et al. 2014; Tatsumi et al. 2008,), and plants (Hu et al. 2009; Huis et al. 2010; Jain et al. 2006; Zemp et al. 2014). In addition, the use of more than one reference gene might be necessary to accurately normalize gene expression levels and avoid relative errors (Jian et al. 2008; Ohl et al. 2005).

Skeletal muscle development is an important subject of biological research, and it plays an important role in meat production and various diseases (Li et al. 2016a; Nixon et al. 2016; Obata et al. 2016; Zabielski et al. 2016, Costa Junior et al. 2016; Fonvig et al. 2015; Putti et al. 2015; Thivel et al. 2016). Studies of muscle development often explore gene expression under different conditions ( Krist et al. 2015; Wang et al. 2016b; Zhang et al. 2016a; Zhang et al. 2015). The expressions of most genes display variable expression levels in prenatal and postnatal periods, and reference genes that are frequently used for other experiments are not suitable for studies of skeletal muscle development. Several studies have been conducted to select reference genes in pigs (Li et al. 2016b; Monaco et al. 2010; Park et al. 2015; Zhang et al. 2012;McCulloch et al. 2012). However, few studies have focused on reference genes in developing skeletal muscle from prenatal to postnatal periods (Wang et al. 2015). To identify and select better reference genes, it is necessary to evaluate the expression of more candidate genes during skeletal muscle development in both prenatal and postnatal periods. We hope to provide valuable information for gene expression analysis during different stages of skeletal muscle development in mammals, which may provide a valuable guide for the analysis of human diseases and a better understanding of muscle development.

In this study, we used transcriptome data (data not shown) from prenatal and postnatal 
82 skeletal muscle combined with previous reports to select 15 candidate reference genes for further

83

84 analysis, including $A C T B, A P I 5, B 2 M, G A P D H, H P A R 1, H 3 F 3$, PPIA, APIS1, DRAP1, RHOA, RPS18, RPL32, TBP, WSB, and VAPB (Martino et al. 2011; Uddin et al. 2011; Wang et al. 2015; Zhou et al. 2014). We collected samples of longissimus dorsi (LD) muscles at 26 developmental stages (including 15 prenatal and 11 postnatal periods) in Landrace pigs (a typical lean-type western breed). The expression stability of these reference genes in the porcine muscle samples was evaluated using qPCR analysis and the expression analysis programs NormFinder (Andersen et al. 2004), BestKeeper (Pfaffl et al. 2004), and geNorm (Vandesompele et al. 2002).

\section{Materials and Methods}

Sample collection ,RNA extraction and next generation sequencing

All animals were sacrificed at a commercial slaughterhouse according to protocols approved by the Institutional Animal Care and Use Committee at the Institute of Animal Science, Chinese Academy of Agricultural Sciences(Approval number: PJ2011-012-03). Longissimus dorsi (LD) muscle samples were collected from Landrace fetuses on the following days post-coitum (dpc): $33,40,45,50,55,60,65,70,75,80,85,90,95,100$, and $105 \mathrm{dpc}$. LD muscle samples were collected from piglets on the following days after birth (dab): 0, 10, 20, 30, 40, 60, 80, 100, 140, 160 , and $180 \mathrm{dab}$. Three biological replicates were collected at each time point, and totally 78 samples were collected. All samples were immediately frozen in liquid nitrogen and stored at $80^{\circ} \mathrm{C}$ until further processing. Total RNA was extracted using TRIzol Reagent (Invitrogen, USA) according to the manufacturer's instructions. RNA quantity and quality was determined by the Evolution 60 UV-Visible Spectrophotometer (Thermo Scientific). RNA preparations with an 
105

106

107

108

109

110

111

112

113

114

115

116

117

118

119

120

121

122

123

124

125

126

127

$\mathrm{A}_{260} / \mathrm{A}_{280}$ ratio of 1.8-2.1 and an $\mathrm{A}_{260} / \mathrm{A}_{230}$ ratio $>2.0$ were selected for this assay. RNA integrity was determined by analyzing the $28 \mathrm{~S} / 18 \mathrm{~S}$ ribosomal RNA ratio on $1.5 \%$ agar gels. Only RNA preparations that resolved with three clear bands on these gels were used for the transcriptome sequencing and qPCR analysis.

\section{Selection of candidate reference genes}

For the purpose of identifying potential reference genes during skeletal muscle development, candidate reference genes were selected according to previous studies (Martino et al. 2011; Uddin et al. 2011; Wang et al. 2015; Zhou et al. 2014). The top 15 stably reference genes in the transcriptome data of skeletal muscle at different developmental stages based on the coefficient of variation $(\mathrm{CV})$ were chosen for further gene-stability evaluation by qPCR method. Lower $\mathrm{CV}$ values represent genes with more stable expression in our transcriptome data.

\section{$c D N A$ synthesis}

The cDNA synthesis was performed using the RevertAid First Strand cDNA Synthesis Kit (Thermo Scientific, USA) according to the manufacturer's instructions for reverse transcription (RT) PCR. A mixture of $2 \mu \mathrm{g}$ of total RNA and $1 \mu \mathrm{L}$ of random primer was incubated at $65^{\circ} \mathrm{C}$ for 5 min to dissociate the RNA secondary structure. Next, the following reaction was carried out in a total volume of $20 \mu \mathrm{L}: 12 \mu \mathrm{L}$ of the first reaction mixture, $4 \mu \mathrm{L}$ of $5 \times \mathrm{RT}$ buffer, $2 \mu \mathrm{L}$ of 10 nM dNTP, $1 \mu \mathrm{L}$ of RevertAid Reverse Transcriptase (200 U/ $\mu \mathrm{l})$ inhibitor, and $1 \mu \mathrm{L}$ RiboLockRNase Inhibitor $(20 \mathrm{U} / \mu \mathrm{l})$. The reverse transcription reaction was performed at $25^{\circ} \mathrm{C}$ for $5 \mathrm{~min}$, followed by $42{ }^{\circ} \mathrm{C}$ for $1 \mathrm{~h}$ and $5 \mathrm{~min}$ at $70^{\circ} \mathrm{C}$. The cDNA was then diluted 7 -fold, and stored at $-20^{\circ} \mathrm{C}$ until use. 
qPCR with SYBR green

130

131

132

133

134

146

Each qPCR reaction was performed in a final reaction volume of $20 \mu \mathrm{L}$ containing $10 \mu \mathrm{L}$ of SYBR Green Select Master Mix, $7 \mu \mathrm{L}$ of sterile water, $0.5 \mu 1$ of gene-specific primers, and $2 \mu \mathrm{L}$ of template cDNA. The PCR amplifications were performed on a 7500 Real-Time PCR System (Applied Biosystems, Foster City, CA, USA) under the following cycling conditions: $95^{\circ} \mathrm{C}$ for 5 min, followed by 40 cycles at $95{ }^{\circ} \mathrm{C}$ for $15 \mathrm{~s}$ and $60{ }^{\circ} \mathrm{C}$ for $45 \mathrm{~s}$. Three independent individuals at each time point were used for temporal and spatial analyses. Each qPCR reaction was performed in triplicate for technical repeats. The mean quantification cycle $(\mathrm{Cq})$ value was used for further analysis. The primer sequences were according to or based on those of previous reports as follows (Table 1): B2M, RHOA, RPL32, DRAP1, RNF7, WSB, and H3F3 (Wang et al. 2015); $A C T B, A P 1 S 1$, API5, and VAPB (Tramontana et al. 2008); GAPDH and RPS18 (Park et al. 2015); and TBP and PPIA (Martino et al. 2011; Uddin et al. 2011).

Analysis of gene expression stability

Gene expression data were transformed to relative quantities using geNorm and NormFinder. GeNorm provided a measure of gene expression stability (M) (Vandesompele et al. 2002;

McCulloch et al. 2012),

$\mathrm{Mj}=\sum_{k=1}^{n} V j k / \mathrm{n}-1 \quad$ where:

$\mathrm{Mj}=$ gene stability measure,

$\mathrm{Vjk}=$ pairwise variation of gene $\mathrm{j}$ relative to gene $\mathrm{k}$,

$\mathrm{n}=$ total number of number of examined genes.

Lower $\mathrm{M}$ values represent genes with more stable expression across specimens being compared 
151 and generated a ranking of the putative reference gene expression levels from the most stable 152 (lowest M-values) to the least stable (highest M-values). GeNorm also generated a pairwise 153 stability measure, which can be used to evaluate the suitable number of reference genes for 154 normalization.

156 NormFinder provided a stability measure (SV), identified the most stable gene, and calculated 157 the best combination of two reference genes. This program focuses on finding the two genes with 158 the least intra- and inter-group expression variation or the most stable reference gene in intragroup expression variation. Genes with lower stability values show a stably expressed pattern, while the higher stability values share the least stably expressed pattern.

The BestKeeper program was used to compute the geometric mean of each candidate gene's $\mathrm{Cq}$ value, to determine the most stably expressed genes based on correlation coefficient (r) analysis for all pairs of candidate reference genes ( $\leq 10$ genes), and to calculate the percentage coefficient of variation $(\mathrm{CV})$ and standard deviation (SD) using each candidate gene's crossing point (CP) value (the quantification cycle value; $\mathrm{Cq}$ ). In the BestKeeper program, genes with higher $\mathrm{r}$ values and lower $\mathrm{CV}$ and $\mathrm{SD}$ values are more stable reference genes.

\section{Results}

Expression analysis of candidate reference genes in developing skeletal muscle

We performed qPCR assays to measure the expression levels of 15 candidate reference genes 
$17470,75,80,85,90,95,100$, and $105 \mathrm{dpc})$ and 11 postnatal stages $(0,10,20,30,40,60,80,100$,

175 140, 160, and $180 \mathrm{dab}$ ) of Landrace pigs. To minimize experimental error, triplicate

176 amplifications were performed for individual experiments. The $\mathrm{Cq}$ values were computed to

177 quantify the candidate reference gene expression levels. A higher Cq value means lower gene

178

179

180

181

182

183 expression levels. Analysis of gene expression stability was based on the Cq values generated by qPCR (Fig. 1). Among all the tested genes, GAPDH had the lowest mean Cq value (15.94) and AP1S1 had the highest mean Cq value (26.36). All candidate reference genes were abundantly expressed in skeletal muscle and showed wide variations in expression levels at different developmental stages. Therefore, it was necessary to evaluate gene expression stability and determine the suitable number of reference genes for accurate gene expression profiling in developing skeletal muscle.

\section{GeNorm analysis of candidate reference gene expression stability}

We calculated the gene expression stability values (M value) for the 15 candidate reference genes using the geNorm program. Genes with lower M values have more consistent expression levels. The M values of the candidate genes are presented in Figure 1. When all developmental stages were analyzed as one data set. The results revealed that API5 and H3F3 had the lowest M values, whereas $G A P D H$ had the highest $\mathrm{M}$ value. This indicated that $A P I 5$ and $H 3 F 3$ were the most stably expressed gene pair of the 15 candidate reference genes, whereas GAPDH had the most variable expression (Fig. 2) in developing skeletal muscle across prenatal and postnatal periods. In the prenatal muscle samples, API5 and RPS18 expression was the most stable, whereas $G A P D H$ and $D R A P 1$ expression was the most variable (Fig. 3). When only postnatal muscle samples were analyzed, $A P I 5$ and RPS18 expression was the most stable, whereas $B 2 M$ expression was the most variable (Fig. 4). The geNorm analysis demonstrated that GAPDH was 
198 the most variably expressed gene in all developmental periods, suggesting that GAPDH was not

199 a suitable reference gene for gene expression analysis in developing skeletal muscle. By contrast, 200 the stability of $A P I 5, R P S 18$, and $H 3 F 3$ expression suggested that they were suitable reference

201 genes to use as internal controls. When gene expression was analyzed in developing skeletal

202 muscle across all tested prenatal and postnatal periods, API5 expression was the most suitable to 203 use as a reference gene for normalization analysis in expression profiling studies.

204 One single reference gene might not provide sufficient control for gene expression analyses 205 in developing skeletal muscle. Therefore, we used geNorm to analyze the optimal number of 206 reference genes required to obtain reliable results from RT-qPCR studies. GeNorm was used to 207 calculate the average pairwise variation (V) value between two sequential normalization factors; 208 it has a cut-off value of 0.15 for the pairwise variation according to the previous study (Wang et 209 al. 2015), below which the inclusion of an additional reference gene is not required for reliable 210 normalization of qPCR analyses. When all developmental stages were analyzed together, the $211 \mathrm{~V}_{\mathrm{n}} / \mathrm{V}_{\mathrm{n}+1}$ value ranged from 0.059 to 0.111 , which were all lower than the cut-off value of 0.15

212 (Fig. 5). These results indicated that two reference genes were optimal for gene expression 213 analysis of all tested developmental periods. The results were similar for gene expression 214 analysis of the embryonic data set (Fig. 6), and two reference genes were sufficient for analysis. 215 By contrast, the $\mathrm{V}$ value decreased significantly with the addition of reference genes in the 216 postnatal data set, although all values were lower than 0.15 (Fig. 7). These results indicated that 217 the three most stable reference genes were required for accurate normalization of gene 218 expression data for the postnatal period. 
221 Next, we used NormFinder to rank the most stable and the least stable genes by calculating the

222 gene expression stability value and standard error. NormFinder analyses showed that API5 was

223 the most stable reference gene with the lowest stability value $(\mathrm{SV}=0.088)$ in all tested

224 developmental periods (Table 2). API5 was the most stable reference gene in postnatal periods, 225 whereas RPS18 was the most stable reference gene in prenatal periods (Table 2).

226

227

228

229

230

231

232

233

234

235

236

237

238

239

240

241

242

243

BestKeeper analysis of candidate reference gene expression stability

Then, BestKeeper program was used to evaluate the reference gene expression stability. We used BestKeeper to identify the optimal reference genes on the basis of the correlation coefficient $(r)$, $\mathrm{CV}$, and SD values (Table 3). The program can calculate $r$ values for up to 10 genes. Therefore, we selected the top 10 candidate genes based on the previous results. In the BestKeeper program, genes with higher $r$ values $(\geq 0.900)$ and lower CV and SD values are considered as stable and suitable reference genes. In all tested developmental periods, API5 expression had the lowest CV value (2.09) and almost the lowest SD value (it was slightly larger than that of RPL32 expression). Therefore, we propose that API5 is the most suitable reference gene for expression analysis of developing skeletal muscle during the tested prenatal and postnatal stages. API5 also was selected as the most stable gene during the postnatal period, whereas $V A P B$ was the most stable gene for the analysis of developing skeletal muscle during the embryonic period.

\section{Discussion}

Studies of muscle development are important to improve meat production, to understand human diseases like diabetes (Li et al. 2016a; Nixon et al. 2016; Obata et al. 2016; Zabielski et al. 2016) and obesity (Costa Junior et al. 2016; Fonvig et al. 2015; Putti et al. 2015; Thivel et al. 
244 2016) due to the important role of skeletal muscle in lipid and energy metabolism. Many studies

245 investigated the mechanism of skeletal muscle development by performing gene expression

246 analysis (Krist et al. 2015; Wang et al. 2016b; Zhang et al. 2016a; Zhang et al. 2015). However,

247 it is crucial to select accurate reference genes to normalize target gene expression levels during

248 skeletal muscle development in mammals. A number of different genes have been commonly

249 used for normalizing gene expression in skeletal muscle, including $A C T B$ and $G A P D H$. It was

250 assumed that the expression of these genes was perfectly stable. However, many experiments

251 have shown that these reference genes have variable expression levels in developing skeletal

252 muscle (Wang et al. 2015, Selvey et al., 2001).

Many researchers have studied the suitable reference genes in pig skeletal muscle. For

example, Feng et al. (2010) found that PPIA and HPRT were the most stable reference genes for gene expression studies in LD muscles of postnatal Yorkshire pigs. Wang et al. (2015) reported that $D R A P 1$ and $R N F 7$ were the most appropriate combination of reference genes to normalize gene expression in postnatal developing muscle of Yorkshire pigs. These previous studies tested only a limited number of candidate reference genes and a limited number of developmental stages. By contrast, we selected many different candidate reference genes and tested gene expression in many developmental stages (essentially covering the whole period of the pig lifespan under investigation). Therefore, the results of our study are more robust and accurate. expression. The results analyzed by three different algorithms (NormFinder, BestKeeper, and geNorm) showed that apoptosis inhibitor 5 (API5) was the best candidate reference gene for normalizing target gene expression in developing skeletal muscle across the tested prenatal and postnatal periods. API5 is highly conserved across species from microorganisms to plants and 
267 animals (Li et al. 2011; Mayank et al. 2015; Noh et al. 2014). AP15 has an important role in

268 negative regulation of apoptotic processes in fibroblasts (Kim et al. 2000; Noh et al. 2014). This

269 gene encodes an inhibitory protein that prevents apoptosis after growth factor deprivation. The

270 API5 protein suppresses apoptosis induced by the transcription factor E2F1, and interacts with

271 and negatively regulates Acinus, a nuclear factor involved in apoptotic DNA fragmentation. The

272 API5 gene is involved in many human diseases including diabetes and cancers (Cho et al. 2014;

273 Noh et al. 2014; Peng et al. 2015; Ramdas et al. 2011). However, API5 has not been reported to

274 be involved in skeletal muscle development. We hypothesize that API5 may play an important

275 role in skeletal muscle development as a housekeeping gene, based on the observed constitutive

276 expression across prenatal and postnatal developing skeletal muscle in pigs.

277 Park et al. (2015) examined the expression stability of different genes in various tissues, and

278 found that PPIA, TBP, RPL4, and RPS18 were the suitable reference genes in Landrace pigs

279 (Park et al. 2015). Our results are consistent with these conclusions. The combination of DRAP1

280 and WSB2 is appropriate for the whole tested developmental period in Tongcheng pigs (an

281 obese-type Chinese native breed) (Wang et al. 2015), whereas our study showed that DRAPl and

$282 R N F 7$ were unsuitable as reference genes in prenatal and postnatal developmental periods in

283 Landrace pigs. These differences may be caused by the developmental stages tested, or that we

284 tested more developmental stages in our study. $H 3 F 3$ was reported as a suitable reference gene in

285 the prenatal period in Tongcheng pigs, which was consistent with the results of our study.

286 We previously reported that $R P L 32, R P S 18$, and $H 3 F 3$ were the most stable reference genes

287 in 33, 65, and 90 dpc skeletal muscle in Landrace pigs (Zhang et al. 2012). The current results

288 also identify these genes as suitable reference genes for normalizing target gene expression in

289 developing skeletal muscle during the prenatal periods. We selected candidate reference genes 
290 during skeletal muscle development based on transcriptome data and previous studies, which

291 might provide a new clue for evaluating the stability of candidate reference genes. Combined

292 with multiple methods, our evaluated results would be more precious and accurate. However, our

293

294

295

296

297

298

299

300

301

302

303

304

305

306

307

308

309

310

311

312

313

314

315

316

present work only evaluated these candidate references on the Landrace pigs. Further studies are needed to further evaluate the stability of these genes during skeletal muscle development at other pig breeds and mammals.

\section{Conclusion}

Our study evaluated the expression stability of 15 candidate reference genes in LD skeletal muscle across 26 prenatal and postnatal developmental periods in Landrace pigs. We found that the commonly used reference genes (GAPDH and $A C T B)$ were not suitable as reference genes for skeletal muscle development. Our results showed that API5, a newly discovered reference gene, was the most suitable reference gene for all tested periods and muscle samples. RPL32, RPS18, $V A P B$, and $H 3 F 3$ also were suitable as reference genes in developing skeletal muscle. Our data provide a guide for choosing appropriate reference genes for studies on skeletal muscle development and diseases in humans and other mammals.

\section{Reference}

Andersen CL, Jensen JL, and Orntoft TF. 2004. Normalization of real-time quantitative reverse transcription-PCR data: A model-based variance estimation approach to identify genes suited for normalization, applied to bladder and colon cancer data sets. Cancer Research 64:5245-5250.

Blaha M, Nemcova L, Kepkova KV, Vodicka P, and Prochazka R. 2015. Gene expression analysis of pig cumulusoocyte complexes stimulated in vitro with follicle stimulating hormone or epidermal growth factor-like peptides. Reproductive Biology and Endocrinology 13:113 
317
Boosani CS, Dhar K, and Agrawal DK. 2015. Down-regulation of hsa-miR-1264 contributes to DNMT1-mediated silencing of SOCS3. Mol Biol Rep 42:1365-1376.

Bustin SA. 2002. Quantification of mRNA using real-time reverse transcription PCR (RT-PCR): trends and problems. J Mol Endocrinol 29:23-39.

Cho H, Chung JY, Song KH, Noh KH, Kim BW, Chung EJ, Ylaya K, Kim JH, Kim TW, Hewitt SM, and Kim JH. 2014. Apoptosis inhibitor-5 overexpression is associated with tumor progression and poor prognosis in patients with cervical cancer. BMC Cancer 14.545

Costa Junior D, Peixoto-Souza FS, Araujo PN, Barbalho-Moulin MC, Alves VC, Gomes EL, and Costa D. 2016. Influence of Body Composition on Lung Function and Respiratory Muscle Strength in Children With Obesity. J Clin Med Res 8:105-110.

Feng XT, Xiong YZ, Qian H, Lei MG, Xu DQ, and Ren ZQ. 2010. Selection of reference genes for gene expression studies in porcine skeletal muscle using SYBR green qPCR. Journal of Biotechnology 150:288-293.

Fonvig CE, Chabanova E, Ohrt JD, Nielsen LA, Pedersen O, Hansen T, Thomsen HS, and Holm JC. 2015. Multidisciplinary care of obese children and adolescents for one year reduces ectopic fat content in liver and skeletal muscle. BMC Pediatr 15:196.

Gabert J, Beillard E, van der Velden VHJ, Bi W, Grimwade D, Pallisgaard N, Barbany G, Cazzaniga G, Cayuela JM, Cave H, Pane F, Aerts JLE, De Micheli D, Thirion X, Pradel V, Gonzalez M, Viehmann S, Malec M, Saglio G, and van Dongen JJM. 2003. Standardization and quality control studies of 'real-time' quantitative reverse transcriptase polymerase chain reaction of fusion gene transcripts for residual disease detection in leukemia - A Europe Against Cancer Program. Leukemia 17:2318-2357.

Ginzinger DG. 2002. Gene quantification using real-time quantitative PCR: An emerging technology hits the mainstream. Experimental Hematology 30:503-512.

Hu RB, Fan CM, Li HY, Zhang QZ, and Fu YF. 2009. Evaluation of putative reference genes for gene expression normalization in soybean by quantitative real-time RT-PCR. BMC Molecular Biology 10:93

Huggett J, Dheda K, Bustin S, and Zumla A. 2005. Real-time RT-PCR normalisation; strategies and considerations. Genes and Immunity 6:279-284.

Huis R, Hawkins S, and Neutelings G. 2010. Selection of reference genes for quantitative gene expression normalization in flax (Linum usitatissimum L.). BMC Plant Biology 10:71.

Jain M, Nijhawan A, Tyagi AK, and Khurana JP. 2006. Validation of housekeeping genes as internal control for studying gene expression in rice by quantitative real-time PCR. Biochem Biophys Res Commun 345:646651 .

Jian B, Liu B, Bi YR, Hou WS, Wu CX, and Han TF. 2008. Validation of internal control for gene expression study in soybean by quantitative real-time PCR. BMC Molecular Biology 9:59.

Kim JW, Cho HS, Kim JH, Hur SY, Kim TE, Lee JM, Kim IK, and Namkoong SE. 2000. AAC-11 overexpression induces invasion and protects cervical cancer cells from apoptosis. Laboratory Investigation 80:587-594.

Krist B, Florczyk U, Pietraszek-Gremplewicz K, Jozkowicz A, and Dulak J. 2015. The Role of miR-378a in Metabolism, Angiogenesis, and Muscle Biology. International Journal of Endocrinology. 281756

Li J, Chen T, Li K, Yan HT, Li XW, Yang Y, Zhang YL, Su BY, and Li FX. 2016a. Neurolytic celiac plexus block enhances skeletal muscle insulin signaling and attenuates insulin resistance in GK rats. Experimental and Therapeutic Medicine 11:2033-2041.

Li X, Huang K, Chen F, Li W, Sun S, Shi XE, and Yang G. 2016b. Verification of suitable and reliable reference genes for quantitative real-time PCR during adipogenic differentiation in porcine intramuscular stromalvascular cells. Animal:1-6.

Li XW, Gao XQ, Wei Y, Deng L, Ouyang YD, Chen GX, Li XH, Zhang QF, and Wu CY. 2011. Rice APOPTOSIS INHIBITOR5 Coupled with Two DEAD-Box Adenosine 5 '-Triphosphate-Dependent RNA Helicases Regulates Tapetum Degeneration. Plant Cell 23:1416-1434. 
Mackay IM. 2004. Real-time PCR in the microbiology laboratory. Clinical Microbiology and Infection 10:190-212.

Martinez-Giner M, Noguera JL, Balcells I, Fernandez-Rodriguez A, and Pena RN. 2013. Selection of Internal Control Genes for Real-Time Quantitative PCR in Ovary and Uterus of Sows across Pregnancy. PloS one 8. e66023

Martino A, Cabiati M, Campan M, Prescimone T, Minocci D, Caselli C, Rossi AM, Giannessi D, and Del Ry S. 2011. Selection of reference genes for normalization of real-time PCR data in minipig heart failure model and evaluation of TNF-alpha mRNA expression. Journal of Biotechnology 153:92-99.

Mayank AK, Sharma S, Nailwal H, and Lal SK. 2015. Nucleoprotein of influenza A virus negatively impacts antiapoptotic protein API5 to enhance E2F1-dependent apoptosis and virus replication. Cell Death \& Disease 6. E2018

McCulloch RS, Ashwell MS, O'Nan AT, and Mente PL. 2012. Identification of stable normalization genes for quantitative real-time PCR in porcine articular cartilage. Journal of Animal Science and Biotechnology 3:36.

Monaco E, Bionaz M, de Lima AS, Hurley WL, Loor JJ, and Wheeler MB. 2010. Selection and reliability of internal reference genes for quantitative PCR verification of transcriptomics during the differentiation process of porcine adult mesenchymal stem cells. Stem Cell Research \& Therapy 1:7

Nixon M, Stewart-Fitzgibbon R, Fu J, Akhmedov D, Rajendran K, Mendoza-Rodriguez MG, Rivera-Molina YA, Gibson M, Berglund ED, Justice NJ, and Berdeaux R. 2016. Skeletal muscle salt inducible kinase 1 promotes insulin resistance in obesity. Mol Metab 5:34-46.

Noh KH, Kim SH, Kim JH, Song KH, Lee YH, Kang TH, Han HD, Sood AK, Ng J, Kim K, Sonn CH, Kumar V, Yee C, Lee KM, and Kim TW. 2014. API5 Confers Tumoral Immune Escape through FGF2-Dependent Cell Survival Pathway. Cancer research 74:3556-3566.

Obata A, Kubota N, Kubota T, Iwamoto M, Sato H, Sakurai Y, Takamoto I, Katsuyama H, Suzuki Y, Fukazawa M, Ikeda S, Iwayama K, Tokuyama K, Ueki K, and Kadowaki T. 2016. Tofogliflozin Improves Insulin Resistance in Skeletal Muscle and Accelerates Lipolysis in Adipose Tissue in Male Mice. Endocrinology 157:1029-1042.

Ohl F, Jung M, Xu CL, Stephan C, Rabien A, Burkhardt M, Nitsche A, Kristiansen G, Loening SA, Radonic A, and Jung K. 2005. Gene expression studies in prostate cancer tissue: which reference gene should be selected for normalization? Journal of Molecular Medicine-Jmm 83:1014-1024.

Park SJ, Kwon SG, Hwang JH, Park da H, Kim TW, and Kim CW. 2015. Selection of appropriate reference genes for RT-qPCR analysis in Berkshire, Duroc, Landrace, and Yorkshire pigs. Gene 558:152-158.

Peng DF, Wang J, Zhang R, Jiang F, Tang SS, Chen M, Yan J, Sun X, Wang SY, Wang T, Yan DD, Bao YQ, Hu C, and Jia WP. 2015. Common variants in or near ZNRF1, COLEC12, SCYL1BP1 and API5 are associated with diabetic retinopathy in Chinese patients with type 2 diabetes. Diabetologia 58:1231-1238.

Pfaffl MW, Tichopad A, Prgomet C, and Neuvians TP. 2004. Determination of stable housekeeping genes, differentially regulated target genes and sample integrity: BestKeeper - Excel-based tool using pair-wise correlations. Biotechnology Letters 26:509-515.

Putti R, Migliaccio V, Sica R, and Lionetti L. 2015. Skeletal Muscle Mitochondrial Bioenergetics and Morphology in High Fat Diet Induced Obesity and Insulin Resistance: Focus on Dietary Fat Source. Front Physiol 6:426.

Ramdas P, Rajihuzzaman M, Veerasenan SD, Selvaduray KR, Nesaretnam K, and Radhakrishnan AK. 2011. Tocotrienol-treated MCF-7 Human Breast Cancer Cells Show Down-regulation of API5 and Up-regulation of MIG6 Genes. Cancer Genomics \& Proteomics 8:19-31.

Robledo D, Hernandez-Urcera J, Cal RM, Pardo BG, Sanchez L, Martinez P, and Vinas A. 2014. Analysis of qPCR reference gene stability determination methods and a practical approach for efficiency calculation on a turbot (Scophthalmus maximus) gonad dataset. Bmc Genomics 15:648

Selvey, S, Thompson, E.W, Matthaei, K, Lea, R.A, Irving, M.G, Griffiths, L.R, 2001. B-Actin—an unsuitable internal control for RT-PCR. Mol. Cell. Probes 15, $307-311$.

Tang Z, Li Y, Wan P, Li X, Zhao S, Liu B, Fan B, Zhu M, Yu M, and Li K. 2007. LongSAGE analysis of skeletal 
muscle at three prenatal stages in Tongcheng and Landrace pigs. Genome Biology 8:R115.

Tatsumi K, Ohashi K, Taminishi S, Okano T, Yoshioka A, and Shima M. 2008. Reference gene selection for realtime RT-PCR in regenerating mouse livers. Biochem Biophys Res Commun 374:106-110.

Thivel D, Ring-Dimitriou S, Weghuber D, Frelut ML, and O'Malley G. 2016. Muscle Strength and Fitness in Pediatric Obesity: a Systematic Review from the European Childhood Obesity Group. Obes Facts 9:52-63.

Tramontana S, Bionaz M, Sharma A, Graugnard DE, Cutler EA, Ajmone-Marsan P, Hurley WL, and Loor JJ. 2008. Internal controls for quantitative polymerase chain reaction of swine mammary glands during pregnancy and lactation. Journal of Dairy Science 91:3057-3066.

Uddin MJ, Cinar MU, Tesfaye D, Looft C, Tholen E, and Schellander K. 2011. Age-related changes in relative expression stability of commonly used housekeeping genes in selected porcine tissues. BMC Res Notes 4:441.

Valasek MA, and Repa JJ. 2005. The power of real-time PCR. Advances in Physiology Education 29:151-159.

Vandesompele J, De Preter K, Pattyn F, Poppe B, Van Roy N, De Paepe A, and Speleman F. 2002. Accurate normalization of real-time quantitative RT-PCR data by geometric averaging of multiple internal control genes. Genome Biology 3:1-12.

Wan HJ, Zhao ZG, Qian CT, Sui YH, Malik AA, and Chen JF. 2010. Selection of appropriate reference genes for gene expression studies by quantitative real-time polymerase chain reaction in cucumber. Analytical Biochemistry 399:257-261.

Wang WW, Liu Y, Wang HF, Ding XD, Liu JF, Yu Y, and Zhang Q. 2016a. A genomic variant in IRF9 is associated with serum cytokine levels in pig. Immunogenetics 68:67-76.

Wang Y, Xiao X, and Wang LJ. 2016b. Molecular characterization and expression patterns of emerin (EMD) gene in skeletal muscle between Meishan and Large White pigs. Gene 579:41-46.

Wang YY, Zhao YQ, Li J, Liu HJ, Ernst CW, Liu XR, Liu GR, Xi Y, and Lei MG. 2015. Evaluation of housekeeping genes for normalizing real-time quantitative PCR assays in pig skeletal muscle at multiple developmental stages. Gene 565:235-241.

Warrington JA, Nair A, Mahadevappa M, and Tsyganskaya M. 2000. Comparison of human adult and fetal expression and identification of 535 housekeeping/maintenance genes. Physiological Genomics 2:143-147.

Wolffs P, Grage H, Hagberg O, and Radstrom P. 2004. Impact of DNA polymerases and their buffer systems on quantitative real-time PCR. Journal of Clinical Microbiology 42:408-411.

Yeung AT, Holloway BP, Adams PS, and Shipley GL. 2004. Evaluation of dual-labeled fluorescent DNA probe purity versus performance in real-time PCR. Biotechniques 36:266-275.

Zabielski P, Lanza IR, Gopala S, Holtz Heppelmann CJ, Bergen HR, 3rd, Dasari S, and Nair KS. 2016. Altered Skeletal Muscle Mitochondrial Proteome As the Basis of Disruption of Mitochondrial Function in Diabetic Mice. Diabetes 65:561-573.

Zemp N, Minder A, and Widmer A. 2014. Identification of Internal Reference Genes for Gene Expression Normalization between the Two Sexes in Dioecious White Campion. PloS one 9.e92893

Zhang J, Tang ZL, Wang N, Long LQ, and Li K. 2012. Evaluating a Set of Reference Genes for Expression Normalization in Multiple Tissues and Skeletal Muscle at Different Development Stages in Pigs Using Quantitative Real-Time Polymerase Chain Reaction. DNA and Cell Biology 31:106-113.

Zhang P, Hou SY, Chen JC, Zhang JS, Lin FY, Ju RJ, Cheng X, Ma XW, Song Y, Zhang YY, Zhu MS, Du J, Lan Y, and Yang X. 2016a. Smad4 Deficiency in Smooth Muscle Cells Initiates the Formation of Aortic Aneurysm. Circulation Research 118:388-399.

Zhang YD, Chen BN, Ming L, Qin HS, Zheng L, Yue Z, Cheng ZX, Wang YN, Zhang DW, Liu CM, Bin W, Hao QZ, Song FC, and Ji B. 2015. MicroRNA-141 inhibits vascular smooth muscle cell proliferation through targeting PAPP-A. International Journal of Clinical and Experimental Pathology 8:14401-14408.

Zhang YX, Li WT, Zhu MF, Li Y, Xu ZY, and Zuo B. 2016b. FHL3 differentially regulates the expression of 
MyHC isoforms through interactions with MyoD and pCREB. Cellular Signalling 28:60-73.

457

458

459

460

461

462
Zhao W, Mu Y, Ma L, Wang C, Tang Z, Yang S, Zhou R, Hu X, Li MH, and Li K. 2015. Systematic identification and characterization of long intergenic non-coding RNAs in fetal porcine skeletal muscle development. Sci Rep 5:8957.

Zhou XH, Liu J, and Zhuang Y. 2014. Selection of appropriate reference genes in eggplant for quantitative gene expression studies under different experimental conditions. Scientia Horticulturae 176:200-207.

10.1016/j.scienta.2014.07.010 
464

465

466

467

468

469

470

471

472

473

474

475

476

477

478

479

480

481

482

483

484

485

486

487

\section{Figure legends}

Figure 1. Box-and-whisker plot displaying the range of $\mathrm{Cq}$ values for each reference gene. The median is marked by the middle line in the box.

Figure 2. Average expression stability (M) of 15 candidate reference genes and the best combination of two genes were calculated for 26 developmental periods. Lower M values indicate more stable expression

Figure 3. Average expression stability (M) of 15 candidate reference genes and the best combination of two genes were calculated for the prenatal periods. Lower M values indicate more stable expression.

Figure 4. Average expression stability (M) of 15 candidate reference genes and the best combination of two genes were calculated for the postnatal period. Lower M values indicate more stable expression.

Figure 5. Determination of the optimal number of reference genes for normalization in the whole tested period by GeNorm . GeNorm was used to calculate the normalization factor (NF) from at least two genes; the variable $\mathrm{V}$ defines the pair-wise variation between two sequential NF values.

Figure 6. Determination of the optimal number of reference genes for normalization in prenatal periods by GeNorm . GeNorm was used to calculate the normalization factor (NF) from at least two genes; the variable $V$ defines the pair-wise variation between two sequential NF values.

Figure 7. Determination of the optimal number of reference genes for normalization in postnatal periods by GeNorm. GeNorm was used to calculate the normalization factor (NF) from at least two genes; the variable $\mathrm{V}$ defines the pair-wise variation between two sequential NF values. 
Figure 1

Box-and-whisker plot displaying the range of $\mathrm{Cq}$ values for each reference gene.

Box-and-whisker plot displaying the range of $\mathrm{Cq}$ values for each reference gene. The median is marked by the middle line in the box.

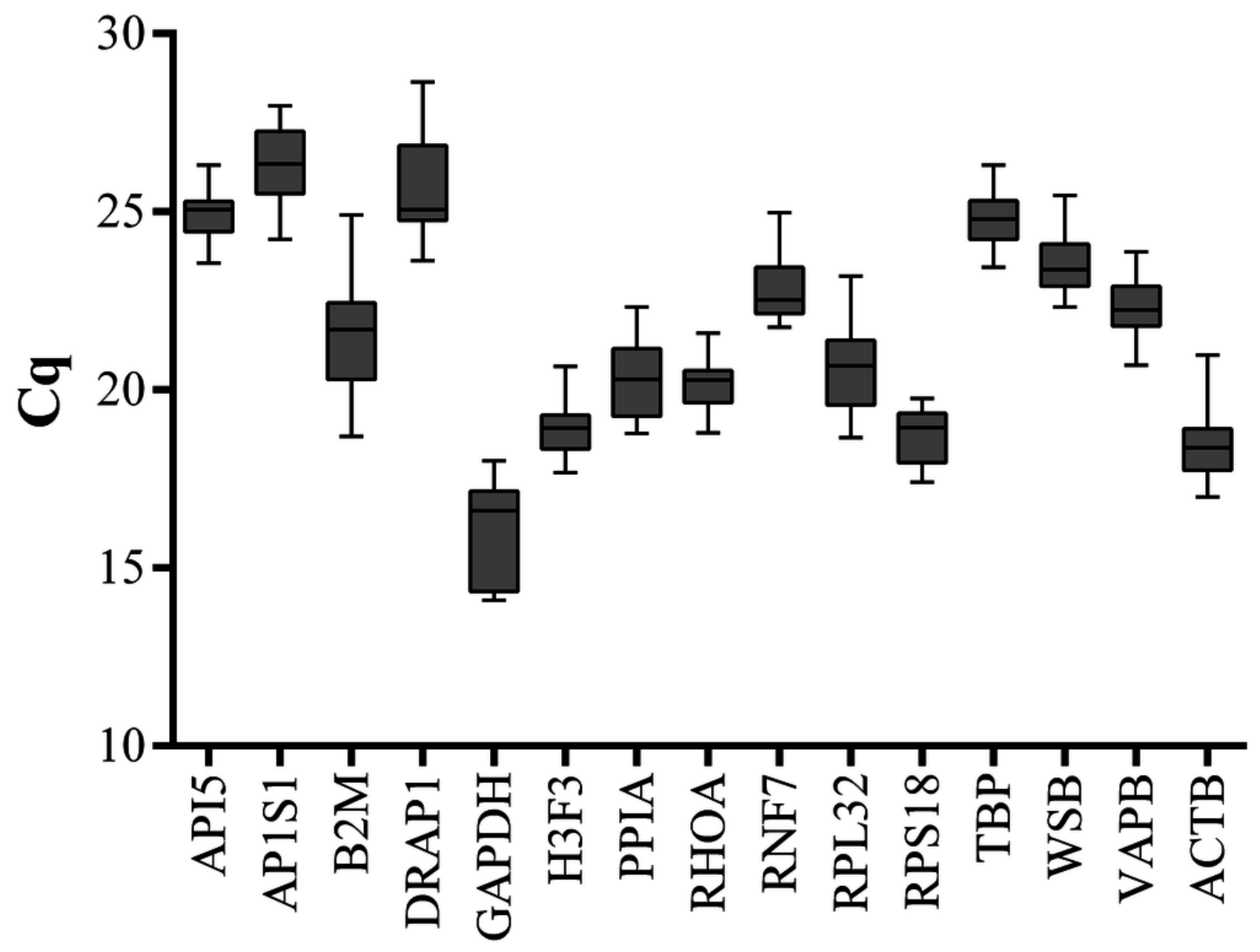

Reference genes 
Figure 2

Average expression stability $(\mathrm{M})$ of 15 candidate reference genes and the best combination of two genes were calculated for 26 developmental periods.

Average expression stability (M) of 15 candidate reference genes and the best combination of two genes were calculated for 26 developmental periods. Lower M values indicate more stable expression.

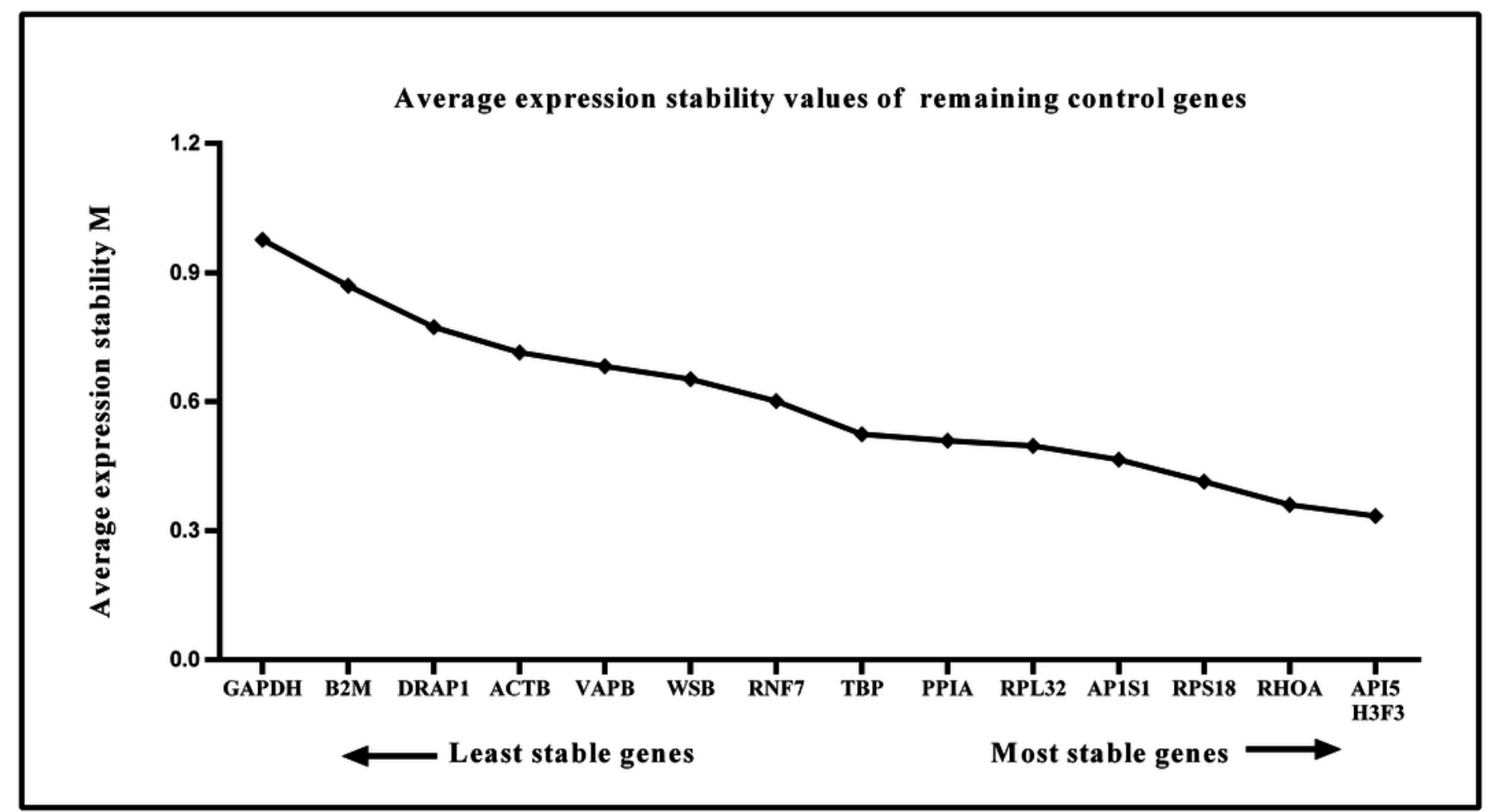


Figure 3

Average expression stability (M) of 15 candidate reference genes and the best combination of two genes were calculated for the prenatal periods.

Average expression stability (M) of 15 candidate reference genes and the best combination of two genes were calculated for the prenatal periods.Lower $\mathrm{M}$ values indicate more stable expression.

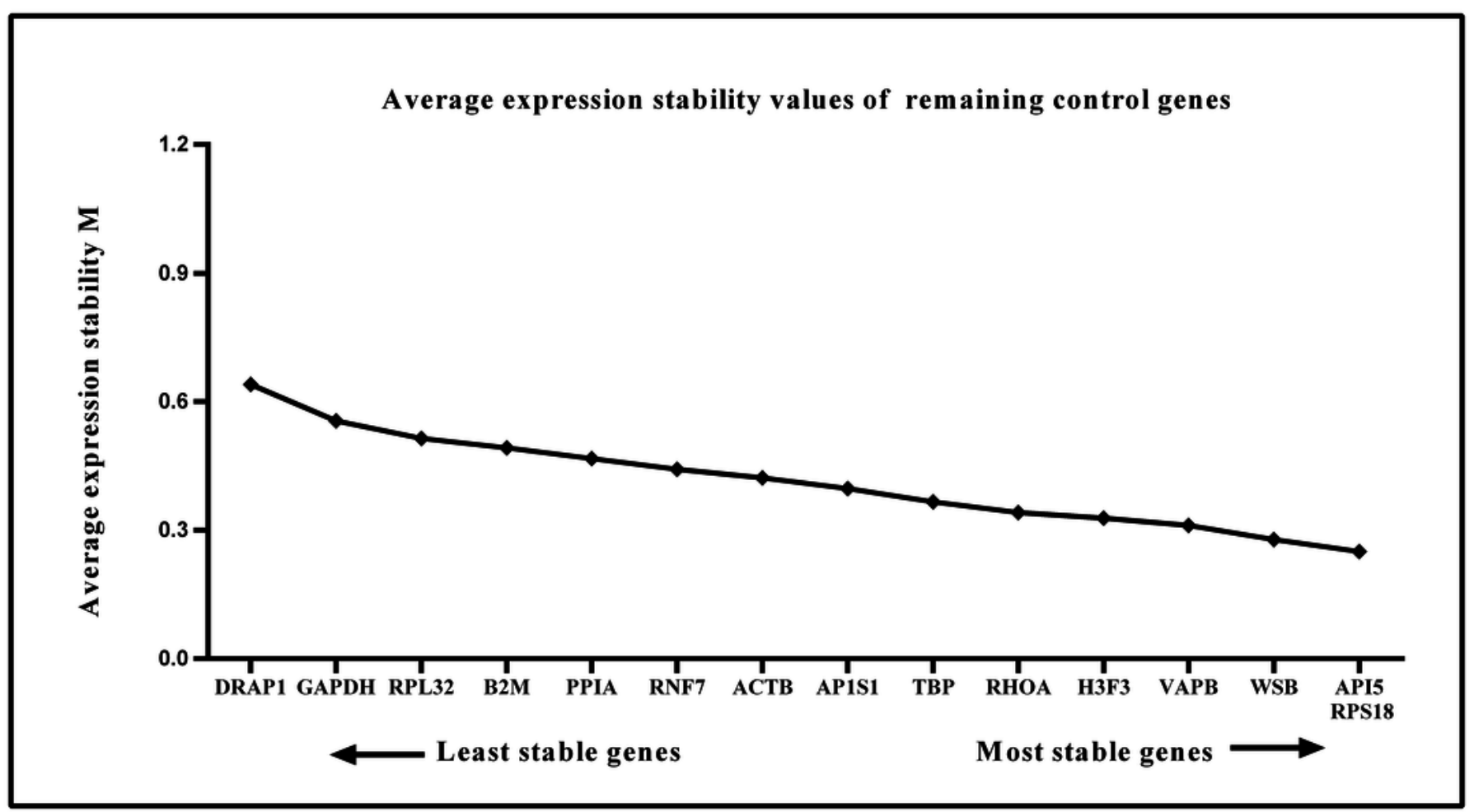


Figure 4

Average expression stability (M) of 15 candidate reference genes and the best combination of two genes were calculated for the postnatal period. Lower $M$ values indicate more stable expression.

Average expression stability (M) of 15 candidate reference genes and the best combination of two genes were calculated for the postnatal period. Lower M values indicate more stable expression.

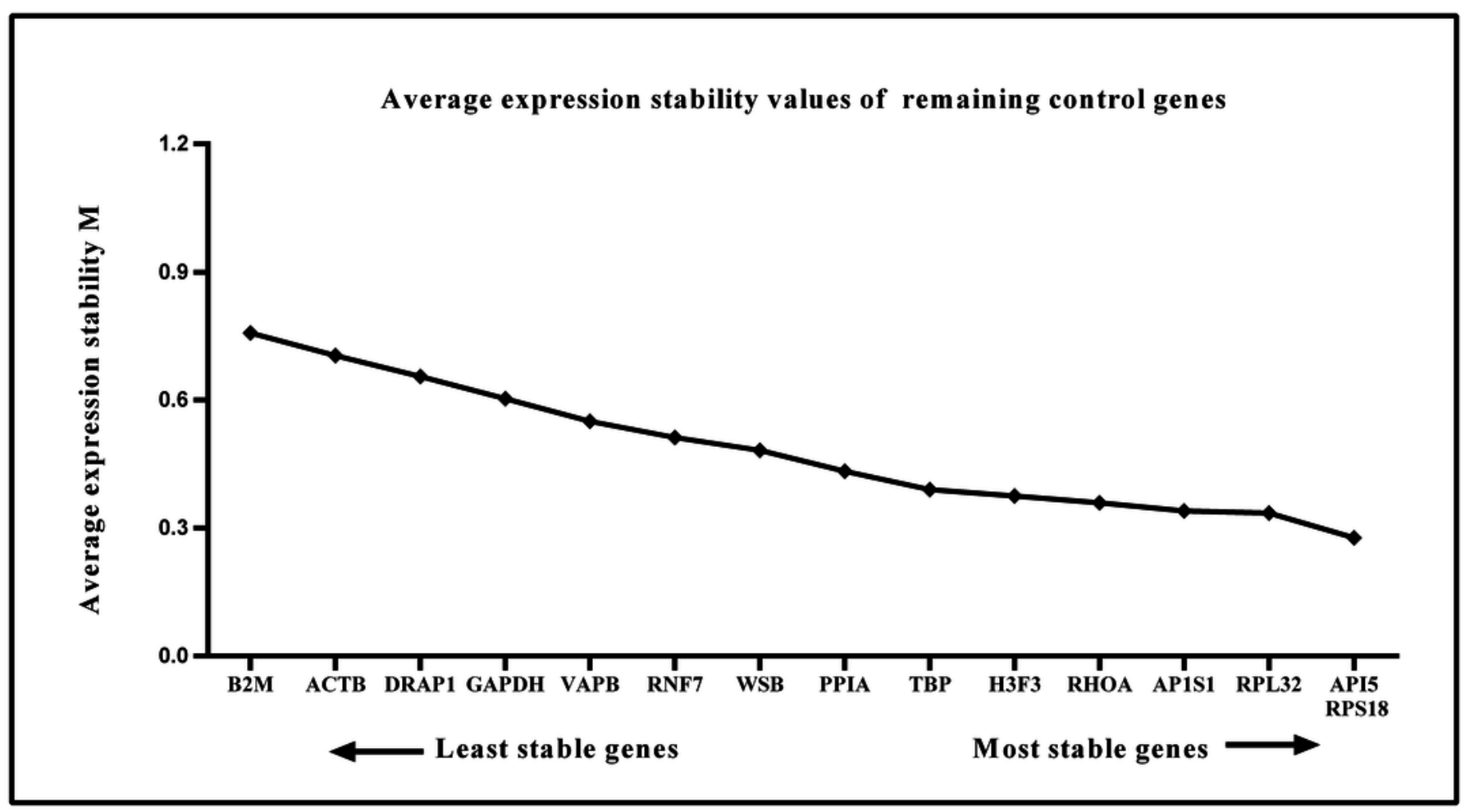




\section{Figure 5}

Determination of the optimal number of reference genes for normalization in the whole tested period.

Determination of the optimal number of reference genes for normalization in the whole tested period. GeNorm was used to calculate the normalization factor (NF) from at least two genes; the variable $V$ defines the pair-wise variation between two sequential NF values.

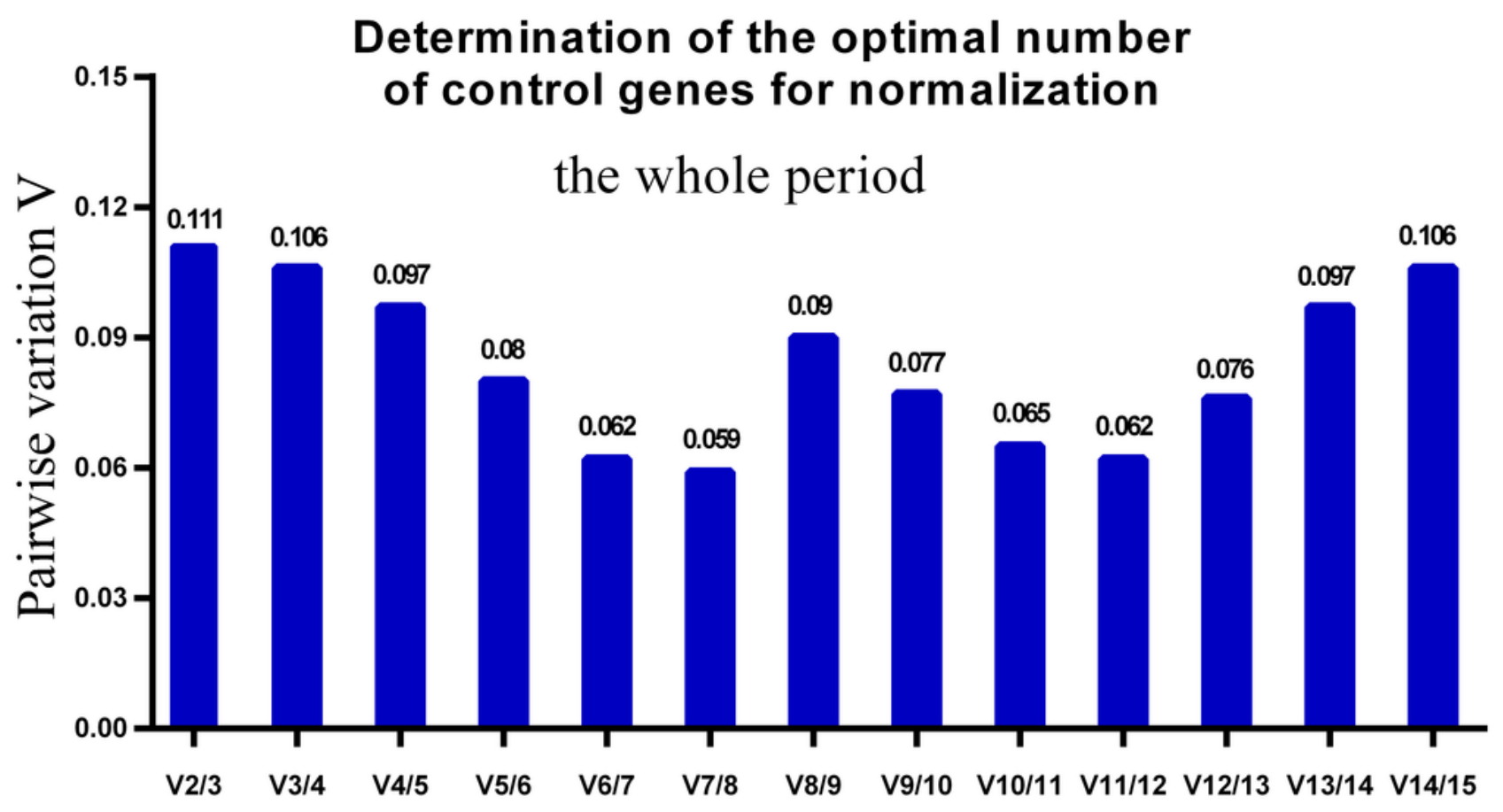




\section{Figure 6}

Determination of the optimal number of reference genes for normalization in prenatal periods.

Determination of the optimal number of reference genes for normalization in prenatal periods. GeNorm was used to calculate the normalization factor (NF) from at least two genes; the variable $V$ defines the pair-wise variation between two sequential NF values.

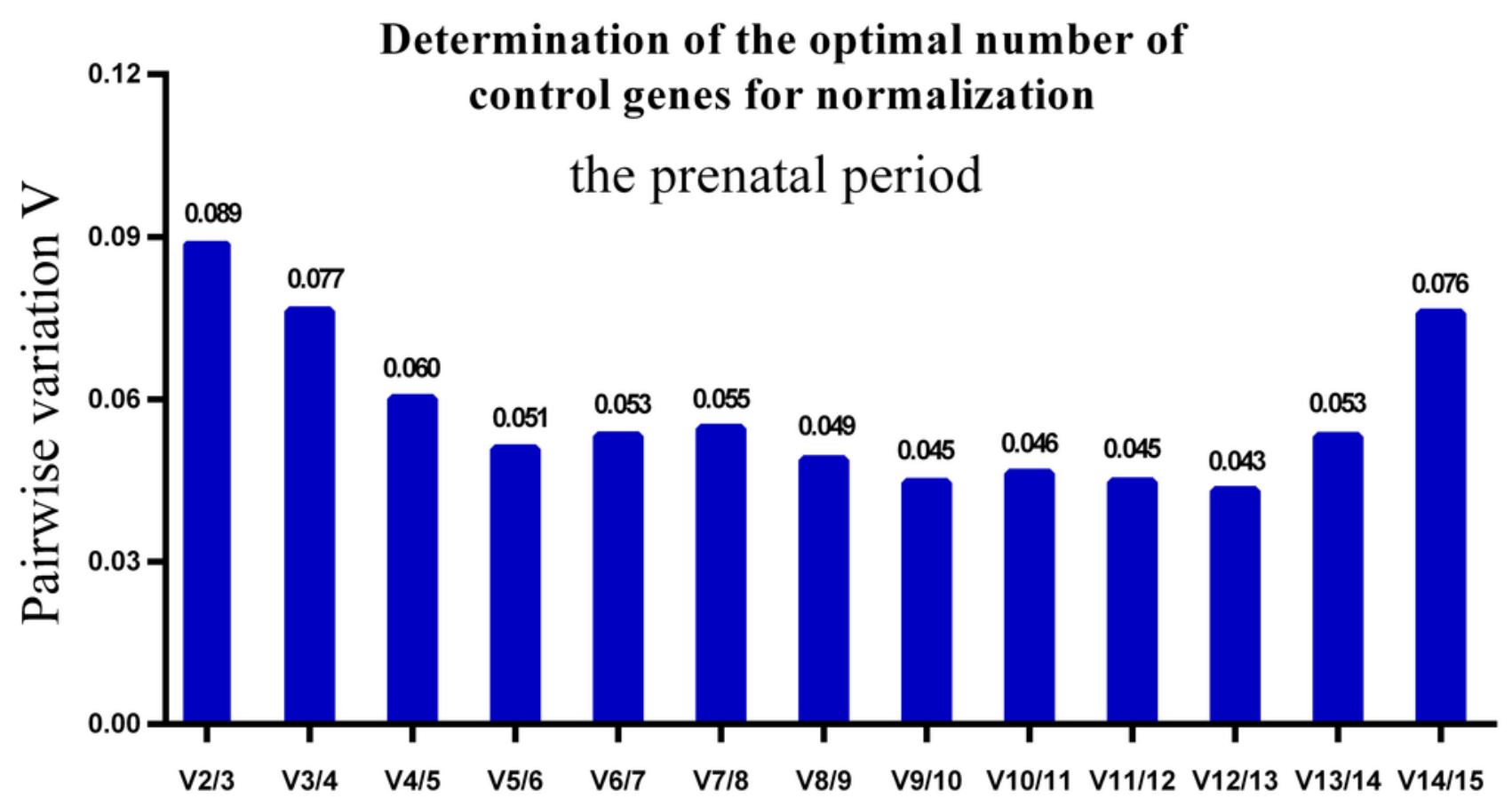




\section{Figure 7}

Determination of the optimal number of reference genes for normalization in postnatal periods.

Determination of the optimal number of reference genes for normalization in postnatal periods. GeNorm was used to calculate the normalization factor (NF) from at least two genes; the variable $V$ defines the pair-wise variation between two sequential NF values.

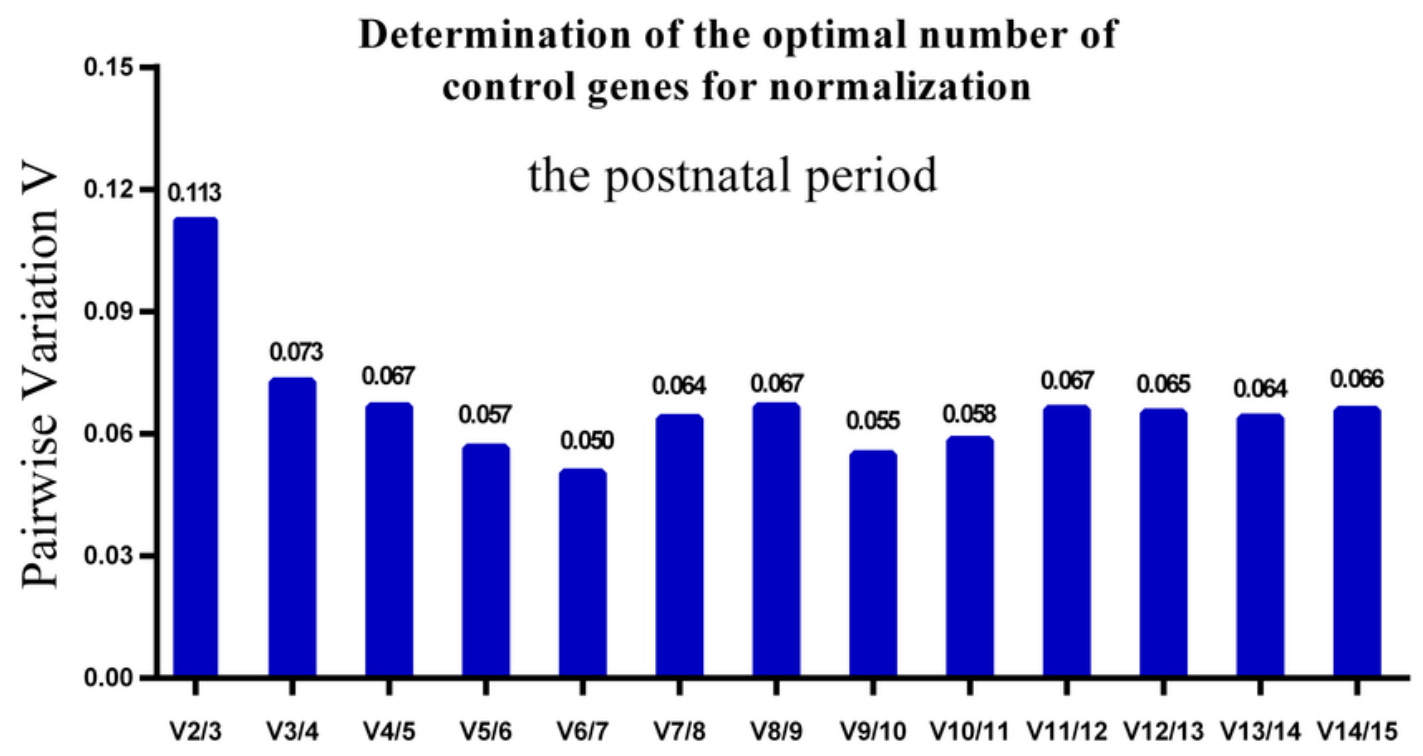




\section{Table 1 (on next page)}

Primers for the 15 candidate reference genes of RT-qPCR data analysis

Primers for the 15 candidate reference genes of RT-qPCR data analysis 


\begin{tabular}{|c|c|c|c|}
\hline $\begin{array}{c}\text { Gene } \\
\text { symbol }\end{array}$ & Gene name & $\begin{array}{l}\text { Amplicon } \\
\text { length(bp) }\end{array}$ & References \\
\hline API5 & Apoptosis inhibitor 5 & 82 & $\begin{array}{l}\text { Tramontana et al. } \\
2008\end{array}$ \\
\hline AP1S1 & AP-1 complex subunit sigma-1A & 100 & $\begin{array}{l}\text { Tramontana et al. } \\
2008\end{array}$ \\
\hline $\mathrm{B} 2 \mathrm{M}$ & Beta-2-microglobulin & 188 & Wang et al. 2015 \\
\hline DRAP1 & $\begin{array}{l}\text { Down-regulator of transcription 1-associated } \\
\text { protein } 1\end{array}$ & 157 & Wang et al. 2015 \\
\hline GAPDH & Glyceraldehyde 3-phosphate dehydrogenase & 130 & Park et al. 2015 \\
\hline H3F3A & $\mathrm{H} 3$ histone, family $3 \mathrm{~A}$ & 181 & Wang et al. 2015 \\
\hline PPIA & Peptidyl-prolylisomerase A (cyclophilin A) & 171 & Uddin et al. 2011 \\
\hline RHOA & Ras homolog A & 167 & Wang et al. 2015 \\
\hline RNF7 & Ring finger protein 7 & 141 & Wang et al. 2015 \\
\hline RPL32 & Ribosomal protein $\mathrm{L} 32$ & 145 & Wang et al. 2015 \\
\hline RPS18 & Ribosomal protein S18 & 74 & Park et al. 2015 \\
\hline TBP & TATA box binding protein & 124 & Martino et al. 2011 \\
\hline WSB & WD repeat and SOCS box-containing & 157 & Wang et al. 2015 \\
\hline VAPB & VAMP-associated protein B & 100 & $\begin{array}{l}\text { Tramontana et al. } \\
2008\end{array}$ \\
\hline ACTB & Beta-actin & 120 & $\begin{array}{c}\text { Tramontana et al. } \\
2008\end{array}$ \\
\hline
\end{tabular}

1 


\section{Table 2 (on next page)}

Calculations of gene stability valueby NormFinder program.

Calculations of gene stability valueby NormFinder program. 
Gene stability value calculations by NormFinder.

\begin{tabular}{cccccc}
\hline \multicolumn{2}{c}{ The whole period } & \multicolumn{2}{c}{ Prenatal period } & \multicolumn{2}{c}{ Postnatal period } \\
\hline Gene & $\begin{array}{c}\text { Stability } \\
\text { value }\end{array}$ & $\begin{array}{c}\text { Gene } \\
\text { name }\end{array}$ & $\begin{array}{c}\text { Stability } \\
\text { value }\end{array}$ & $\begin{array}{c}\text { Gene } \\
\text { name }\end{array}$ & $\begin{array}{c}\text { Stability } \\
\text { value }\end{array}$ \\
\hline AIP5 & 0.088 & RPS18 & 0.101 & AIP5 & 0.167 \\
H3F3 & 0.150 & AIP5 & 0.112 & RHOA & 0.173 \\
RHOA & 0.242 & H3F3 & 0.146 & H3F3 & 0.193 \\
RNF7 & 0.354 & WSB & 0.172 & RPL32 & 0.236 \\
PPIA & 0.373 & RHOA & 0.176 & AP1S1 & 0.238 \\
WSB & 0.378 & VABP & 0.233 & TBP & 0.284 \\
RPS18 & 0.394 & AP1S1 & 0.25 & RNF7 & 0.303 \\
VABP & 0.422 & RNF7 & 0.281 & RPS18 & 0.308 \\
RPL32 & 0.429 & PPIA & 0.293 & WSB & 0.351 \\
TBP & 0.434 & TBP & 0.31 & PPIA & 0.368 \\
AP1S1 & 0.468 & B2M & 0.339 & VABP & 0.501 \\
ACTB & 0.546 & ACTB & 0.352 & GAPDH & 0.501 \\
DRAP1 & 0.700 & RPL32 & 0.369 & DRAP1 & 0.541 \\
B2M & 0.865 & GAPDH & 0.549 & ACTB & 0.598 \\
GAPDH & 1.096 & DRAP1 & 0.786 & B2M & 0.677 \\
\hline
\end{tabular}




\section{Table 3(on next page)}

Expression stability analysis of the reference genes by BestKeeper.

Expression stability analysis of the reference genes by BestKeeper. 


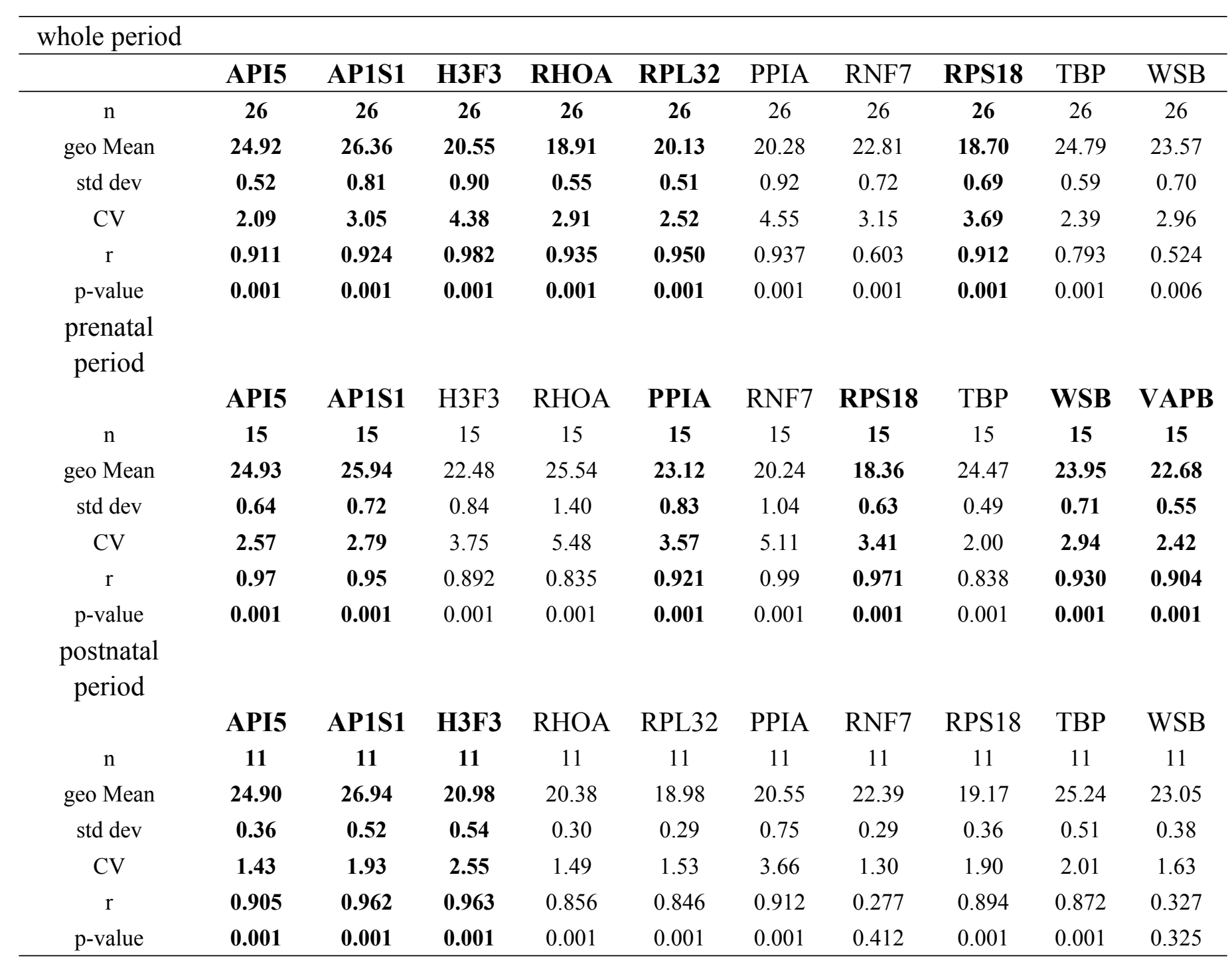

